\title{
A day with an orthoptist
}

\author{
Jeffrey Law (Meds 2016), Charles Yin (MD/PhD 2021)
}

Reviewer: Charla Snow, BSc, OC(C)

\section{CASE PRESENTATION}

The patient was only 6 years old but he had already been to the hospital almost a dozen times. Today, as he was led to the examination room, he clung tightly to his mother's side. When asked to take a seat in the examination chair, he began to cry. Although he had been to the hospital more often than most kids his age, he clearly didn't find the setting enjoyable and he didn't want to be separated from his mother.

The patient had mild exotropia (outward deviation of the eyes) from an early age. While he had never explicitly complained of vision problems, he had a history of squinting frequently and turning his head in an attempt to see more clearly. His mother, on several occasions, had further suspected him of "seeing double". On examination, the patient was diagnosed with amblyopia and strabismus, and placed under the care of Charla, an orthoptist at St. Joseph's Hospital, London.

On this occasion, the patient was very distraught by being in the examination room. Charla was reluctant to have him take a seat because he obviously wanted to be with his mother. Luckily, Charla had a number of toys she kept in the office that she was able to take out and have the patient play with to distract him.

The clinical exam comprised of a cover test for type of ocular deviation, horizontal and vertical prism bars to measure the size of strabismus, Worth's four light test for assessing degree of binocular vision and suppression and having the patient go through an image book and choose the image that looked "3D" in order to assess binocular vision.

Over the course of the 30-minute appointment, a drastic change overcame the demeanor of the patient. He had transformed from being quite distressed to more comfortable and actually seemed to enjoy the various "games" that made up his exam. The patient and his parents left the office with instructions to patch the unaffected eye in order to strengthen the muscles in the weaker eye and restore proper vision and alignment.

\section{DISCUSSION}

The 6-year-old boy with amblyopia and strabismus was one of many patients I saw with an orthoptist during an observership in the ophthalmology clinic at St. Joseph's Hospital. Prior to my observership, I had never even heard of the profession. Luckily, I got to spend the day with Charla Snow, a practicing orthoptist at St. Joseph's.
Orthoptists are allied health professionals who specialize in the study of eye movements, eye alignment and binocular vision. ${ }^{1}$ Orthoptists work closely with ophthalmologists in managing disorders such as amblyopia and strabismus. While ophthalmologists formulate and implement surgical interventions, orthoptists provide primary care in the assessment, diagnosis and non-surgical treatment of optical complaints. ${ }^{1}$

Strabismus is a condition in which the eyes are not properly aligned. It is caused by an inherently misaligned eye or by a lack of coordination between the extraocular muscles, preventing the eyes from being able to focus on the same point in space. ${ }^{2}$ Symptoms include diplopia, eyestrain and loss of depth perception. ${ }^{2}$ In young patients such as the 6-year-old from the case presentation, strabismus is particularly worrisome because of the risk of developing amblyopia, a condition in which the brain compensates for the lack of ocular alignment by suppressing vision in one eye. ${ }^{3}$ The result is a form of cortical blindness where connections between the eye and the brain do not develop properly and the brain consequently ignores the images coming from that eye. ${ }^{3}$ In the management of strabismus and amblyopia, orthoptists use a combination of glasses, occlusion (patching) and prism therapy. ${ }^{1}$ Orthoptists also monitor and reinforce the treatment plan by meeting with the patients on a regular basis and offer support and guidance to the patient and his or her family. ${ }^{1}$

Orthoptists work with a patient population that ranges from infants just a few months old to seniors, but the majority of their practice deals with children. As such, orthoptists have special skills that facilitate working with this age range. ${ }^{1}$ In general, children have shorter attention spans and are more difficult to examine than adults. ${ }^{4}$ As such, orthoptists use a variety of tests designed to work within the brief window of a child's attention span. For example, in order to check extraocular eye movements, Charla would have the children track a toy with their eyes. The tests are also customized for various age groups: the younger children were given the simpler task of naming shapes, while the older children were given the more complex task of naming letters.

During my day at the clinic, I learned that orthoptics training is at least two years in length following an undergraduate degree, and often includes a third thesis year for the completion of a master's degree. ${ }^{5}$ The curriculum involves learning the unique anatomy, physiology and clinical skills required to excel in such a specialized career. Just like medical schools, orthoptics programs in Canada are accredited by the Canadian Medical Association and all trainees must write a 3-part national examination set by the Canadian Orthoptic Council. ${ }^{5}$ 
When we had a break between patients, I asked Charla where orthoptists fit into the larger scheme amongst optometrists, ophthalmologists and general practitioners. I was told that her practice has a very specialized scope of practice and orthoptists are able to specialize in studying ocular motility and visual development. ${ }^{1} \mathrm{Al}$ though orthoptists cannot perform surgeries and require an ophthalmologist to work with them, having an orthoptist involved in patient care means the management and treatment can be monitored more closely, enhancing the quality of patient care and overall sense of patient satisfaction. ${ }^{6,7}$

\section{CONCLUSION}

Towards the end of the day, I asked whether Charla ever ran into conflicts with other members of the ophthalmology team. She told me that having the ophthalmology clinic centralized at one hospital makes them a tight-knit group and contributes towards a high level of interprofessional collegiality. Although there are occasionally differing opinions on the final diagnosis or different thoughts about how a patient should be managed, Charla emphasized the importance of trusting the skills that each specialty brings to the table. Spending the day in clinic with Charla really brought home to me that, regardless of what medical specialty I end up choosing, developing a trusting and respectful relationship with allied health professionals and working together effectively would be critical to providing the best patient care possible.

\section{REFERENCES}

1. The Canadian Orthoptic Society [Internet]. What do orthoptists do? Canada: The Canadian Orthoptic Society; 2015 [Cited 2015 Jan 11]. Available from: http://www.tcos.ca/english/about_orthoptics/index. php

2. McManaway JW III, Frankel CA. Strabismus. In: Primary Pediatric Care, Hoekelman RA (Ed), Mosby, St. Louis 2001.

3. Coats DK, Paysse EA. Overview of amblyopia. In: UpToDate, Saunders RA (Ed), UpToDate, Waltham, MA. [Cited 2015 Jan 11].

4. Punch S. Research with children: the same or different from research with adults. Childhood. 2002;9(3):321-41.

5. The Canadian Orthoptic Society [Internet]. How do I become an orthoptist? Canada: The Canadian Orthoptic Society; 2015. [Cited 2015 Jan 11]. Available from: http://www.tcos.ca/english/about_orthoptics/ becominganorthoptist.php

6. Ferrari S, Ponzin D, Ashworth JL, Fahnehjelm K-T, Summer CG, Harmatz PR, Scarpa M. Diagnosis and management of ophthalmological features in patients with mucopolysaccharides. Br J Ophthalmol. 2011;95(5):613-9.

7. Jones SA, Shinton RA. Improving outcome in stroke patients with visual problems. Age Ageing. 2006;35(6):560-5.

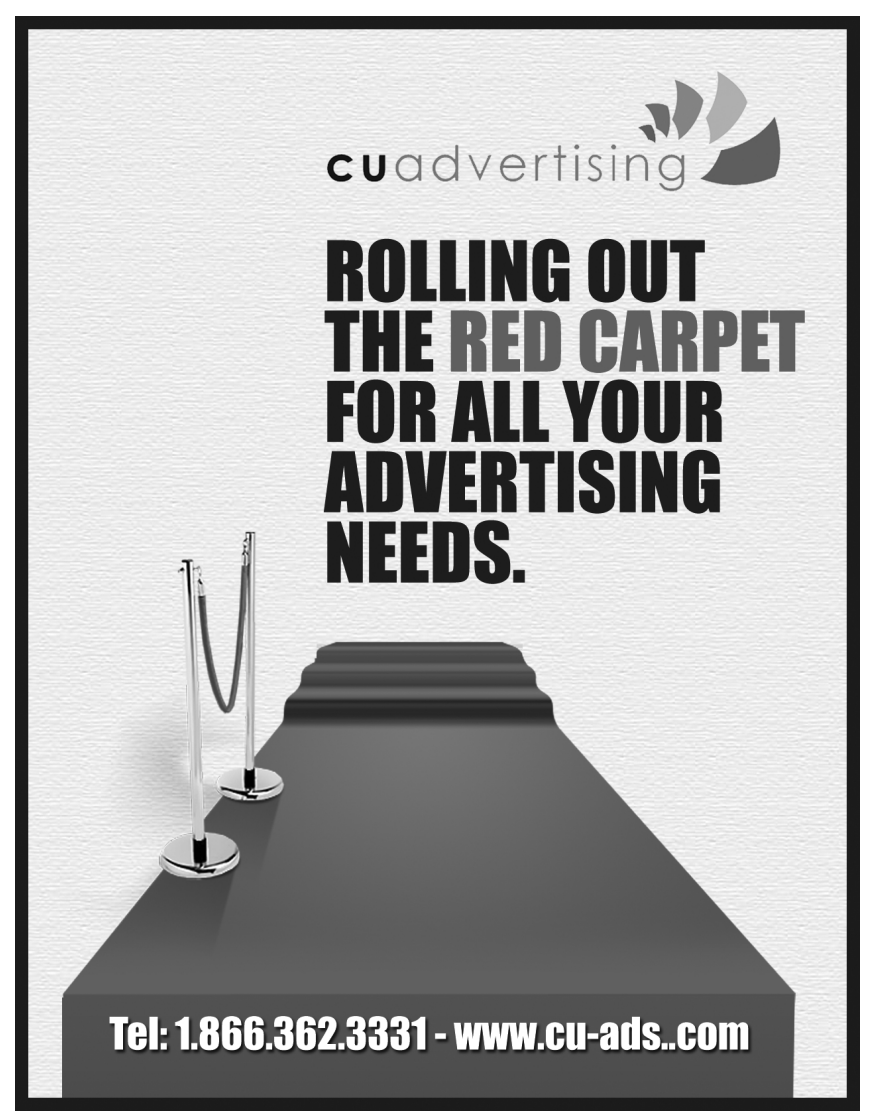

Tol: 1.866.362.3331 - wwW.ell-ads.com 